\title{
Estratégia de negociação do pesquisador com o discurso do outro em seu dizer
}

Sulemi Fabiano Campos* Janima Bernardes Ribeiro"

\section{Resumo}

$\mathrm{O}$ presente estudo analisa duas dissertações de mestrado defendidas em Programa de Pós-graduação em Letras, coletadas no Portal de Periódicos da Capes, produzidas nos anos de 2007 e 2013, em universidades federais brasileiras. O objetivo principal é analisar o uso das formas linguísticas que inscrevem o outro na linearidade do discurso, focalizando as estratégias mobilizadas pelo pesquisador (autor da dissertação) na negociação com o discurso do outro em seu dizer, no texto produzido. Para orientar as reflexões, este estudo mobiliza, principalmente, os estudos linguístico-enunciativos desenvolvidos por Authier-Revuz (1990, 1998, 2004, 2011) sobre a heterogeneidade enunciativa do dizer e busca respaldo no conceito de paráfrase linguística de Fuchs (1985). A análise dos dados mostrou as dificuldades que envolvem o processo de escrita na universidade em relação ao uso das formas linguísticas de introduzir o dizer do outro no texto produzido e problematizar a produção resultante desse processo.

Palavras-chave: Dissertação de mestrado. Formas linguísticas. Negociação de dizeres.

\section{Introdução}

Este trabalho é um recorte de uma pesquisa ${ }^{1}$ realizado no Grupo de Pesquisa em Estudo do Texto e do Discurso (Geted/UFRN). ${ }^{2}$ Investigamos como se manifestam as formas de heterogeneidade mostrada no discurso - termo postulado por Authier-Revuz (2004) -, isto é, o conjunto de formas linguísticas que inscrevem o outro na linearidade do discurso, para verificar quais estratégias são mobilizadas pelo pesquisador na negociação com o discurso do outro em seu dizer no desenvolvimento da escrita

\footnotetext{
Doutora em Linguística e Língua Portuguesa (Unesp). Professora do Departamento de Letras e do Programa de Pós-Graduação em Estudos da Linguagem (PPgEL/ UFRN). Líder do Grupo de Pesquisa em Estudos do Texto e do Discurso (Geted). E-mail: sulemifabiano@ yahoo.com.br

** Doutoranda do Programa de Pós-Graduação em Estudos da Linguagem (PPgEL) da Universidade Federal do Rio Grande do Norte (UFRN). Integrante do Grupo de Pesquisa em Estudos do Texto e do Discurso (Geted/ UFRN).E-mail: janimabernardesribeiro@yahoo.com.br
}

Data de submissão: mar. 2017 - Data de aceite: mar. 2017 http://dx.doi.org/10.5335/rdes.v13i1.6782 
acadêmica. Temos como hipótese que a negociação de vozes evidencia a relação do pesquisador (autor da dissertação) com o discurso do outro no desenvolvimento da pesquisa. A negociação de vozes na escrita da dissertação de mestrado configura-se como necessária na construção de um trabalho de escrita, não apenas para expor ideias dos autores citados, mas também para estabelecer um elo de concordância/discordância entre discursos para a construção de um novo sentido a partir das formas de introduzir o dizer do outro no texto produzido pelo pesquisador.

Procuramos identificar: a) que formas linguísticas são utilizadas pelo pesquisador para inserir o discurso do outro nos textos produzidos; b) como se dá a construção de sentidos do texto considerando-se a negociação de dizeres materializados textualmente. Essas indagações, que serão respondidas ao longo do trabalho, têm como desafio: analisar uma produção discursiva (acadêmico-científica) considerando a materialidade do texto, o modo como os pesquisadores mobilizam o discurso do outro como apoio teórico em seus textos e, além disso, problematizar a produção resultante desse processo.

Trata-se de uma pesquisa de base qualitativa e de caráter descritivo e interpretativo, uma vez que a análise perpassa, primeiramente, pelo limite restrito das formas linguísticas para abordar os modos de organização e funcionamento do texto acadêmico- -científico, que exige dos pesquisadores um atravessamento com a diversidade de dizeres e de "já ditos" na lida com seu objeto de pesquisa. Tomamos como corpus duas dissertações de mestrado. Para compor esse corpus, foi feita uma consulta on-line no Portal de Domínio Público - Capes. Como critério de seleção, foram escolhidas dissertações cujos capítulos teóricos discorrem sobre uma temática comum - Análise do Discurso francesa -, produzidas nos anos de 2007 e 2013, em Programas de Pós-graduação em Letras, em diferentes universidades federais brasileiras. Como recorte metodológico, o autor da dissertação será denominado neste trabalho de pesquisador.

As etapas de análise consistem em identificar e descrever as marcas linguísticas de utilização do discurso do outro em dissertação, em seguida, interpretá-las, colocando em discussão os efeitos de sentido que essa disposição de vozes produz. Esse procedimento de análise pauta-se na metodologia de pesquisa em ciências humanas e sociais, "com procedimentos mais ou menos sistemáticos de coleta e tratamento do material" (CHARAUDEAU, 2011, p. 2), com o intuito de mostrar quais os efeitos de sentido produzidos no texto do pesquisador a partir do modo de utilização do discurso do outro na construção de sentido do texto.

Como fundamentação teórica, buscamos respaldo, principalmente, em postulados de Authier-Revuz (1990, 1998, 2004, 2011), no que se refere à heterogeneidade enunciativa do dizer, 
considerando uma dada manifestação da linguagem, dentro da qual são recortados fatos (todo fenômeno que serve para explicitar o emprego de certas marcas, formas linguísticas e discursivas que funcionam como pistas, e que serão interpretados, os efeitos de sentido que se presentificam no enunciado, nos manejos do sujeito na e pela linguagem na negociação com o discurso do outro no campo científico).

Feita essa introdução, discorremos, no próximo tópico, sobre a heterogeneidade enunciativa, focalizando, conceitualmente, a heterogeneidade mostrada e a heterogeneidade constitutiva. Em seguida, apresentamos os dados da pesquisa, analisando fragmentos representativos recortados em duas dissertações de mestrado. E, por fim, apresentamos nossas considerações finais, em que recuperamos os resultados deste trabalho, elencando alguns pontos que consideramos significativos.

\section{A heterogeneidade enunciativa}

Authier-Revuz (1990, 1998, 2004, 2011) inscreve seus estudos no terreno da enunciação. Para fundamentar a noção de heterogeneidade enunciativa, a autora dialoga com exteriores teóricos (o dialogismo do círculo de Bakhtin e a psicanálise de Freud marcada por Lacan - acerca do descentramento do sujeito). Tal atravessamento pode ser observado nas formas da heterogeneidade mostrada, as quais tomam, no processo enunciativo, a função de emergentes da heterogeneidade constitutiva, isto é, elas representam uma "negociação" obrigatória do pesquisador falante com a heterogeneidade que o constitui.

Authier-Revuz (2004) distingue duas realidades elementares em sua abordagem: "as formas de heterogeneidade constitutiva $d o$ discurso e as formas de heterogeneidade mostrada no discurso" (AUTHIER-REVUZ, 2004, p. 23, grifos do autor). Focando mais detalhadamente sobre a heterogeneidade mostrada no discurso, a autora afirma:

No fio do discurso que, real e materialmente, um locutor único produz, um certo número de formas, linguisticamente detectáveis no nível da frase ou do discurso, inscrevem, em sua linearidade, o outro (AUTHIER-REVUZ, 2004, p. 12, grifos do autor).

emos, assim, um locutor único que produz enunciado e aponta para uma concepção de pesquisador presente nos estudos sobre as heterogeneidades. Com isso, reconhece a enunciação como o $l u$ gar de uma inevitável heterogeneidade de uma incompletude. Desse modo, o centro da relação está no espaço discursivo criado entre ambos, assim, o sujeito só se completa na interação com o outro.

Como resultado, o sujeito é visto como uma exterioridade necessária à constituição da língua. Dito de outro modo, o sujeito é produzido pela linguagem como estruturalmente clivado pelo inconsciente, ele "fala sem o saber de um outro lugar" (AUTHIER-REVUZ, 1998, p. 187), ainda que permaneça, para ele, a ilusão 
do centro, que consiste em pensar que é ele a fonte, a origem do sentido do que diz, de ter o controle das palavras. Essa ilusão é essencial à constituição da língua. É um sujeito que assegura a ilusão do UM, permitindo ao sujeito funcionar como não um (AUTHIER-REVUZ, 1998, p. 187-188), porque na sua fala outras vozes falam. Afinal, várias vozes podem ser ouvidas no mesmo discurso.

Nesse processo, o sujeito toma a palavra, mas a palavra não é sua, vem de algum lugar. Para a constituição de um discurso que se relaciona a outro já dito (PÊCHEUX, 1997). O modo como Authier-Revuz (1990) concebe o sujeito na abordagem das heterogeneidades entende que o dizer não é transparente, sendo esse atravessado pelo inconsciente e pelo interdiscurso. Em outras palavras, o dizer escapa dos domínios do enunciador.

Authier-Revuz (1990, 2004), para estudar a interferência do discurso do outro no discurso do sujeito, classifica a heterogeneidade em duas ordens diferentes, a saber: mostrada e constitutiva. A distinção entre heterogeneidade mostrada no discurso e heterogeneidade constitutiva do discurso torna-se relevante neste trabalho. A autora denomina heterogeneidade mostrada a forma explícita da constituição heterogênea do sujeito, como sendo a inscrição do discurso do outro no discurso do sujeito, assinalando a fronteira entre o externo e o interno no fio do discurso.
A heterogeneidade mostrada pode ser apresentada na superfície textual de dois modos: a) marcada (heterogeneidade visível na materialidade linguística - as formas linguísticas estão claramente delimitadas no discurso, podendo ser assinaladas e descritas, da ordem da enunciação), apresentando marcas textuais, tais como o discurso direto, o discurso indireto, as aspas, e o metadiscurso do enunciador; b) não marcada (sem visibilidade, é mais velada, já que a delimitação das formas linguísticas não é facilmente reconhecida, mas pode ser recuperável, da ordem do discurso), na qual não existe uma ruptura sintática, sem marcas gráficas visíveis, em que "o elemento mencionado é inscrito na continuidade sintática do discurso" (AUTHIER-REVUZ, 1990, p. 29), como é o caso do discurso indireto livre e da ironia.

Cada um desses modos representa suas características linguísticas e semânticas específicas e assinala a heterogeneidade no discurso. Somente a heterogeneidade mostrada e marcada torna-se passível de formalização pela Linguística, justamente porque atribui ao outro um lugar linguisticamente descritível, claramente delimitado no discurso, isto é, apresenta pistas recuperáveis na superfície do discurso. Ao contrário da heterogeneidade mostrada, a heterogeneidade constitutiva é avessa a qualquer modo linguístico de descrição devido à sua presença implícita no discurso do sujeito, mas pode definir, por meio de hipóteses com 
base no interdiscurso - "os discursos já-ditos” (PÊCHEUX, 1990, p. 54), dada a interpelação ideológica dos sujeitos das formações discursivas.

A heterogeneidade mostrada e a constitutiva são designadas como "alteridade representada por formas observáveis na linguagem" e a "alteridade constitutiva, apontando para a relação com o outro que o dizer produz" (AUTHIER-REVUZ, 2011, p. 6). A heterogeneidade é colocada como condição para o discurso e tanto a mostrada quanto a constitutiva são irredutíveis uma a outra, mas, ao mesmo tempo, inseparáveis, visto que uma é a representação da outra no plano do discurso, ou seja, há uma heterogeneidade constitutiva que eventualmente se mostra no dizer.

$\mathrm{O}$ estudo da heterogeneidade enunciativa do dizer torna-se fundamental, visando compreender as marcas na língua que evidenciam a representação da voz do outro no texto produzido pelo sujeito, focando mais detalhadamente nas formas de representação do discurso do outro (RDO), tais como discurso direto, discurso indireto, modalização em discurso segundo. A esse respeito, acreditamos que, no entrecruzamento de vozes que se fazem presentes na estrutura da língua, é possível compreender a relação de sentido da leitura que o pesquisador faz do texto fonte (teórico citado), por meio de negociação de vozes ao citar e/ ou parafrasear uma informação/ideia.

Na seção a seguir, retomamos brevemente o artigo A paráfrase linguística de Fuchs (1985), em especial, acerca da noção de paráfrase como reformulação.

\section{A paráfrase linguística}

Fuchs (1985) ressalta que falar em paráfrase é pensar em algo que não é transparente, pois o próprio termo em questão pode recobrir os mais variados estatutos. A categoria paráfrase é, pois, multifacetada. Fuchs diz: "a paráfrase é um dado imediato da consciência linguística dos locutores" (1985, p. 129, grifo do autor) (algo que lhes permite produzir e identificar frases como tendo o mesmo sentido), mas é também um construto teórico do linguista. Ela é uma atividade linguistica dos sujeitos (um trabalho que implica interpretação e reformulação, mas é, igualmente, o objeto linguístico resultante desta atividade, a saber, enunciado ou texto que reformula outro. E é, ainda, uma relação entre um enunciado ou texto fonte e sua(s) reformulação(ões) efetiva(s) numa situação dada (dimensão sintagmática da cadeia discursiva), mas é também "uma relação entre todos os enunciados virtualmente equivalentes na língua" (no plano paradigmático do sistema da língua).

Tendo exposto essa multiplicidade, Fuchs (1985) centra os estudos da paráfrase, basicamente, em três perspectivas principais, quais sejam: 1) a paráfrase na perspectiva lógica como equivalência formal entre frases; 2) a paráfrase na perspectiva gramatical da sinonímia de frases; e 3) a paráfrase na perspectiva re- 
tórica da reformulação (que efetivamente nos interessa), que será apresentada em forma de resumo.

Fuchs (1985) explica a perspectiva que toma a paráfrase como uma atividade de reformulação textual, no plano do discurso, como atividade efetiva de reformulação pela qual o locutor restaura (bem ou mal, na totalidade ou em partes, fielmente ou não) o conteúdo de um texto fonte sob a forma de um texto segundo. A paráfrase assemelha-se à tradução interlingual,

[...] e a consideração de parâmetros ligados ao locutor e à situação particular de discurso é explícita: é o estudo dos tipos de reformulações a adotar em função do contexto e das circunstâncias que constitui, aqui, o objetivo (FUCHS, 1985, p. 133-134).

Isso significa que devemos considerar a relação do sujeito com a língua e, consequentemente, os efeitos de sentido manifestados na ação de parafrasear e do próprio contexto da enunciação. A paráfrase linguística permite manifestar como um texto se constrói a partir de outro, e pode revelar a construção ou a reconstrução do sentido do texto, do discurso de si e/ou do outro, na composição da sua escrita.

Fuchs (1985), orientada por perspectivas teóricas distintas, quais sejam: a pragmática, a enunciativa e a discursiva, que se destacam por levantar questões como: 1) o fato de a reformulação "repousar sobre uma prévia interpretação do 'texto-fonte"' (FUCHS, 1985, p. 134). Essa interpretação é variável tanto em relação à situação de comunicação como aos seus próprios participantes, o que implica afirmar que a interpretação de um texto não é uma, mas marcada por disseminação de sentidos, já que, segundo a autora, cada um "percebe" e, consequentemente, restaura o texto de modo diferente. Diante disso, a construção de enunciados comporta sempre uma margem de "jogo", margem essa que permite deslocamentos e ponderações; 2) o propósito de refletir sobre a oscilação da paráfrase "entre a reprodução pura e simples do conteúdo e a sua deformação" (FUCHS, 1985, p. 134), considerando-se que o novo texto, assim como o texto fonte, é interpretado pelo pesquisador no momento mesmo em que ele o produz como paráfrase. Essa identificação é momentânea e frágil, resultado de um "apagamento" de diferenças e, por isso, há possibilidade de gerar polêmicas, como: "mas isso não é o que quer dizer o texto (ou seu autor), oscila assim, entre reprodução pura e simples do conteúdo e a sua deformação" (FUCHS, 1985, p. 134).

A reformulação parafrástica traduz-se por formas características do emprego metalinguístico da linguagem. Para Fuchs (1985), a função metalinguística da linguagem possibilita, no momento da comunicação entre locutor e alocutário, decidir o signo linguístico que melhor traduza outro signo em termos de sentido, segundo a autora, por meio de esquemas do tipo: "X, quero dizer $\mathrm{Y} ; \mathrm{X}$, em outras palavras Y". Se, por um lado, a paráfrase é entendida como mecanismo estrutural, por outro, implica considerar a exterioridade, os respectivos participantes e a situação de comunicação. 
Segundo Fuchs (1985), a relação da paráfrase ocorre entre textos (texto fonte $x$ paráfrase). Nesse contexto, a perspectiva da paráfrase no âmbito da reformulação nos interessa para análise da escrita das dissertações de mestrado que compõem o nosso corpus, sobretudo na retomada do texto fonte, na seção da fundamentação teórica, quando o sujeito, nesse caso, o pesquisador, recorre a vários modos de utilização do discurso do outro na construção da sua pesquisa. Assim, na reformulação parafrástica, é possível identificar e analisar os modos de utilização do discurso do outro ao mobilizar, na fundamentação teórica da pesquisa, o referencial teórico, como o sujeito utiliza as ideias teóricas na análise do corpus da pesquisa, bem como depreender uma série de efeitos de sentido.

A paráfrase, entre tantas outras estratégias de reescrita, é recorrente na escrita acadêmica e pode ser recuperada por meio de esquemas estruturais sintáticos. Define uma maneira específica de incorporação e possibilita ao analista recuperar o texto fonte por meio de marcas linguísticas que denotam a organização do texto feita por um terceiro. De modo geral, o pesquisador recorre à paráfrase para reproduzir a ideia do outro, às vezes, por meio de palavras diferentes, as quais, talvez, têm a intenção de facilitar e simplificar determinados conceitos e afirmações, e, além disso, é entendida enquanto criação. A partir do exposto, passamos a mostrar ao leitor os fragmentos representativos recortados em duas dissertações de mestrado analisadas. Utilizamos o termo pesquisador (autor das dissertações) nas análises.

\section{Análise da escrita de dissertação}

Nesta seção, fazemos uma análise qualitativa em duas dissertações de mestrado defendidas em Programas de Pós-graduação em Letras, na área de Análise do Discurso, selecionadas no Banco de Teses da Capes ${ }^{3}$ - no Portal de Periódicos da Capes, produzidas nos anos de 2007 e 2013, em universidades federais brasileiras. Elas serão denominadas como D1 (Dissertação 1) e D2 (Dissertação 2), que indica a ordem de aparição da dissertação; as universidades federais serão identificadas pelas letras A e B. Os pesquisadores, "autores das dissertações", serão identificados pelas combinações D1A e D2B (= dissertação 1, 2, da universidade federal A, B). A partir delas, tentamos responder às seguintes perguntas para este estudo: a) que formas linguísticas são utilizadas pelo pesquisador para inserir o discurso do outro nos textos produzidos?; b) como se dá a construção de sentidos do texto considerando-se a negociação de dizeres materializados textualmente? Para isso, apresentamos fragmentos representativos constatados na análise do corpus em dois capítulos específicos: Fundamentação teórica (aparece mais recorrente na escrita do pesquisador a referência ao discurso do outro - autor 
citado) e Análise dos dados (os conceitos nos resultados dos dados). A seguir, apresentamos um fragmento representativo, na íntegra, de cada capítulo.

Quadro 1 - Fragmento representativo do capítulo de fundamentação teórica - D1A

Para Brandão (2007, p. 50), cabe à AD trabalhar seu objeto (o discurso) inscrevendo-o na relação da língua com a história, buscando na materialidade linguística as marcas das contradições ideológicas. Analisar o discurso é fazer desaparecer e reaparecer as contradições, é mostrar o jogo que jogam entre si; é manifestar como pode exprimi-las, dar Ihes corpo, ou emprestar-lhes uma fugidia aparência. Brandão salienta que é dessa forma que Foucault vê uma FD, e complementa, como sendo um espaço de disseminações múltiplas em que atuam oposições cujos níveis e papéis devem ser descritos não com o objetivo de nivelá-las ou pacificá-las em formas gerais de pensamento.

(D1A, p. 60)

Nesse fragmento, temos um exemplo denominado por Authier-Revuz (2004) de modalização em ou por discurso segundo (MDS) - sobre o conteúdo. Um discurso que, no momento em que se faz, remete-se a outro discurso. As palavras introduzidas por "Para Brandão (2007, p. 50)" não são assumidas pelo pesquisador, ou seja, mostra que está se apoiando no discurso do outro, apresenta o nome do autor, o ano e a página de onde parte para enunciar. Constatamos também o uso de um introdutor típico de discurso indireto (verbo + que), nesse caso, o verbo salienta, seguido de "que", a saber: Brandão salienta que. O pesquisador mobiliza essas formas de representação do discurso do outro para se "esconder" atrás desses discursos. Essa ação se dá pelo fato de que a MDS, além de ser uma forma simples e discreta, contribui para esse distanciamento de quem escreve em relação ao discurso do outro, e também pode ser compreendida como uma tentativa do pesquisador de redizer o dizer do outro (teórico citado), uma atitude avaliativa que, pelas marcas linguísticas lexicais e sintáticas, não recobre o dizer do outro, ou seja, uma enunciação sobre a enunciação que não foi bem sucedida.

Ao evidenciar, a negociação do pesquisador com o discurso do outro no texto produzido, recorremos à fonte teórica (informação fornecida por ele na fundamentação teórica da pesquisa ao citar o nome do autor e até mesmo a página) para entender como o discurso do outro é mobilizado pelo pesquisador na construção do seu texto. Recortamos o trecho representativo do texto fonte (autor citado) e, em seguida, a parte recortada da fundamentação teórica da dissertação do pesquisador, fazendo coincidir um com 0 outro (grifo nosso na amostra ${ }^{4}$ ), para as comparações que pretendemos elencar, de acordo com os propósitos da pesquisa. Desse modo, objetivamos compreender a relação de sentido da leitura que o pesquisador faz desse texto fonte, por meio de negociação de vozes na escrita da pesquisa. Representamos segmentos do texto fonte, seguidos dos segmentos do texto do pesquisador, como se vê no Quadro 2, a seguir. 
Quadro 2 - Segmentos do texto fonte e do texto do pesquisador

Texto 1 - Segmentos do texto fonte: Brandão (2007)

Cabe a AD trabalhar seu objeto (o discurso) inscrevendo-o na relação da língua com a história, buscando na materialidade linguística as marcas das contradições ideológicas. Repetindo ainda Foucault (1986, p. 187), "analisar o discurso fazer desaparecer e reaparecer as contradições: e mostrar o jogo que jogam entre si; manifestar como pode exprimí-las, dar-lhes corpo, ou emprestar-lhes uma frígida aparência". E nesse sentido, ainda, que ele vê uma FD como um "espaço de dissenções múltiplas" em que atuam oposições (a contradição entre a unidade e a diversidade, entre a coerência e a heterogeneidade) cujos níveis e papéis devem ser descritos não com o objetivo de nivelá-las ou pacificá-las em formas gerais de pensamento, mas de demarcar "o ponto em que elas se constituem de definir a forma que assumem, as relações que tem entre si e o domínio que elas comandam" (p. 192).

(BRANDÃO, 2007, p. 50-51)

Texto 2-Segmentos do texto do pesquisador: Fundamentação teórica (FT)

Para Brandão (2007, p.50), cabe à AD trabalhar seu objeto (o discurso) inscrevendo-o na relação da língua com a história, buscando na materialidade linguística as marcas das contradições ideológicas. Analisar o discurso é fazer desaparecer e reaparecer as contradições, é mostrar o jogo que jogam entre si; é manifestar como pode exprimí-las, dar lhes corpo, ou emprestar-lhes uma fugidia aparência. Brandão salienta que é dessa forma que Foucault vê uma FD, e complementa, como sendo um espaço de disseminações múltiplas em que atuam oposições cujos níveis e papéis devem ser descritos não com o objetivo de nivelá-las ou pacificá-las em formas gerais de pensamento.

(D1A, p. 60)

A heterogeneidade mostrada no discurso em Authier-Revuz (2004) refere-se à inscrição do discurso do outro no discurso do sujeito, assinalando a fronteira entre o externo e o interno no fio do discurso. Essa autora explica que a heterogeneidade mostrada pode ser apresentada na superfície textual de forma marcada - visível na materialidade linguística. As formas linguísticas estão claramente delimitadas no discurso, podendo ser assinaladas e descritas, da ordem da enunciação, apresentando marcas textuais, tais como o discurso direto, o discurso indireto, as aspas e o metadiscurso do enunciador.

Ao compararmos os segmentos do texto do pesquisador com os segmentos do texto fonte (autor citado), constatamos que não temos a inscrição do discurso do outro no discurso do pesquisador. No trabalho, denominamos o discurso "outro" (a presença do discurso do teórico citado) e o discurso do pesquisador (o "um", aquele que escreve), que se apropria do discurso do "outro" (teórico) à medida que negocia sentidos.

Temos, nesse fragmento, no modo como o pesquisador negocia com uma heterogeneidade presente em suas palavras, a "inversão de papéis", isto é, o discurso "um" não é do pesquisador, mas do teórico citado, e o discurso "outro" mostrado, que deveria ser referente ao discurso do teórico, refere-se ao discurso do pesquisador que toma o discurso do outro e "negocia" algumas formas de entrada de "si" (inserção do "eu" no texto produzido). Isso pode ser comprovado a partir das estratégias linguísticas de referência ao discurso do outro na materialidade do texto produzido pelo pesquisador. 
Nesse caso, o pesquisador utiliza a forma linguística de modalização de discurso segundo (MDS) no trecho:

Para Brandão (2007, p. 50), cabe a AD trabalhar seu objeto (o discurso) inscrevendo-o na relação da língua com a história, buscando na materialidade linguística as marcas das contradições ideológicas [...].

Nesse excerto, a única diferença na construção de escrita do pesquisador em relação ao texto fonte está justamente na modalização do discurso segundo, que se refere às formas de Representação do Discurso Outro (RDO) no discurso, sendo que o restante do parágrafo segue literalmente o texto fonte (destaque em negrito no Quadro 2).

Com isso, ao utilizar a estratégia de modalização de discurso segundo "Para Brandão (2007)", o pesquisador não faz o trabalho que implica interpretação e reformulação do discurso do autor citado paráfrase linguística -, que ocorre entre textos (texto fonte x paráfrase), porque a diferença se dá justamente devido ao acréscimo introdutor desse modalizador seguido do trecho do teórico, sem uma interpretação do discurso do outro (teórico citado). Nesse caso, o discurso do "um" não é do pesquisador, mas, sim, de Brandão, e o "outro" seria o pesquisador tentando pincelar uma estratégia de inserção no texto produzido a partir do emprego do modalizador como introdutor no enunciado.

Constatamos a forma linguística "Brandão salienta que", introdutor típico de discurso indireto (verbo + que), ou seja, o verbo salienta seguido de "que", no modo como o pesquisador mobiliza o discurso do teórico em seu texto. Ao compararmos o trecho produzido pelo pesquisador com o texto fonte, observamos que o discurso do pesquisador deveria ser o "um", no texto produzido, ao negociar o sentido do texto lido e representado na dissertação, mas continua sendo o "outro" na pesquisa.

Nos segmentos do texto fonte, Brandão (2007), no trecho: "Repetindo ainda Foucault (1986, p. 187), 'analisar o discurso fazer desaparecer e reaparecer as contradições: e mostrar o jogo que jogam entre si; manifestar como pode exprimi-las, dar-lhes corpo, ou emprestar-lhes uma frígida aparência", Brandão cita, entre aspas, uma ideia apresentada por Foucault, menciona o ano e a página de onde retira as ideias do teórico para situar o leitor de onde vem o discurso que cita em seu texto. Observamos que o pesquisador, ao interpretar o conteúdo do texto fonte, por exemplo, a passagem dita por Foucault (1986), faz referência explícita a Brandão. Assim, soa que a passagem é de autoria de Brandão e não de Foucault (1986), na forma como retoma essa passagem dita por Brandão ao citar Foucault. O pesquisador não menciona o que Brandão diz, baseado no dizer de Foucault (1986), constrói o seguinte enunciado: “[...] Brandão salienta que é dessa forma que Foucault vê uma FD, e complementa, como sendo [...]". O uso do verbo complementa ( $3^{\mathrm{a}}$ pessoa, no tempo presente) causa ambiguidade, pois há dúvida sobre o sujeito do verbo, 
pode ser Brandão ou Foucault que complementa, como consequência, a quem classificar como locutor da informação colocada como um complemento do que foi dito anteriormente?

Além disso, o pesquisador utiliza a estratégia de escrita por meio de substituições de palavras, por exemplo, no texto fonte, o trecho: "É nesse sentido, ainda, que ele vê uma FD como um 'espaço de dissenções múltiplas' em que atuam oposições [...]", comparado com o trecho da fundamentação teórica do pesquisador: "Brandão salienta que é dessa forma que Foucault vê uma FD, e complementa, como sendo um espaço de disseminações múltiplas em que atuam oposições [...]", a estrutura permanece a mesma, com substituições das expressões anafóricas, por exemplo: nesse sentido por dessa forma, o pronome relativo ele por Foucault e a substituição da palavra dissenções por disseminações. No texto fonte, temos: "como um 'espaço de dissenções múltiplas' em que atuam oposições [...]", já no texto do pesquisador temos: "como sendo um espaço de disseminações múltiplas em que atuam oposições [...]".

No trecho "Brandão salienta que", o emprego do verbo salienta refere-se ao próprio discurso de Brandão, autora citada. Trata-se de uma estratégia linguística por meio de verbos no presente, na $3^{\mathrm{a}}$ pessoa do singular, sendo possível observar que o pesquisador fica somente no discurso do teórico citado. $\mathrm{O}$ movimento de escrita, o "um" no trecho seria o discurso de Brandão (2007), e o "outro" o discurso do pesquisador, que, na tentativa de negociar sentidos no texto produzido, acaba desempenhando o papel de "outro", devido às manobras que faz a partir da inserção do modalizador "Para Brandão" e do introdutor de discurso indireto "Brandão salienta que", além das substituições de palavras, sendo que a estrutura segue a mesma do texto fonte.

O pesquisador desempenha o "outro" na pesquisa, justamente por tomar a palavra do autor, demostrando não negociar com a heterogeneidade presente em suas palavras, isto é, toma a palavra do outro (autor citado) como tentativa de inscrição de "si". Assim, o "um" na escrita da pesquisa, que deveria ser do pesquisador (aquele que escreve) negociando com o discurso do outro (autor citado), acaba por fazer a inversão de posições no fio do discurso, ou seja, o "um" refere-se ao teórico e o "outro", ao pesquisador, tentado dizer algo, a partir das pistas recuperáveis na superfície do discurso. A fronteira entre o discurso externo, que deveria ser do autor citado, acaba sendo do pesquisador; já o discurso interno, que deveria ser do pesquisador, pertence ao autor citado, nesse caso, Brandão (2007).

O Fragmento 2 enfoca, especialmente, um trecho do capítulo de análise dos dados da dissertação (D2B). O pesquisador busca interpretar um conceito teórico, o que consiste na necessidade de retomar a bibliografia lida na análise dos dados da pesquisa desenvolvida. Em direção oposta ao fragmento anteriormente 
analisado, temos o discurso do outro, a saber: Maingueneau (1997), e o discurso do pesquisador "um" (aquele que escreve). Percebemos que o pesquisador, ao mobilizar o discurso do outro a partir da negociação de sentidos no texto produzido, repete a análise de Maingueneau na frase que analisa para a confirmação de um conceito. Assim, o Fragmento 2 ilustra essa ocorrência no texto produzido pelo pesquisador, apresentado no Quadro 3.

\section{Quadro 3 - Fragmento 2 representativo do capí-} tulo de análise dos dados - D2B

Segmentos do texto do pesquisador: Análise dos dados

2.3 A palavra se materializa

Quando se marca uma palavra com aspas, segundo Authier-Revuz (1998), está se mantendo essa palavra à distância, ou seja, afastando essa palavra do texto em geral. Ao mesmo tempo em que a palavra é sentido usado, ela é mencionada, sendo assim algo de material.

Na frase:

(6) "Que pena que só sei escrever quando espontaneamente a "coisa" vem." [...]

Maingueneau (1997) acrescenta que, diferentemente de uma expressão aspeada de um discurso direto - que remete à alteridade - a palavra entre aspas é utilizada para marcar uma menção e um uso dessa palavra, bem como já foi visto em Authier-Revuz. Nesse caso, a palavra coisa é ao mesmo tempo mostrada, marcada como estranha e integrada à sequência do discurso. [...] A escritora utiliza as aspas para questionar o caráter completamente apropriado da palavra coisa [...].

(D2B, p. 90-91)

No Fragmento 2, temos o caso do modalizador em discurso segundo (MDS): "Segundo Authier-Revuz (1998)," se- guido do parafraseamento do dizer da autora, como se vê no primeiro parágrafo. Centramos a análise com ênfase na parte destacada (sublinhada, segundo e terceiro parágrafos) para demonstrar como o pesquisador faz referência ao discurso do outro (autor citado) ao analisar uma frase em sua pesquisa, a saber: "Que pena que só sei escrever quando espontaneamente a 'coisa' vem. [...]”. É visível que o pesquisador faz recorrência à forma linguística "Maingueneau (1997) acrescenta que", introdutor típico de discurso indireto (verbo + que), o verbo acrescenta, seguido de "que", no modo como mobiliza o discurso do outro em seu texto, mais especificamente, retoma uma explicação do autor referente ao conteúdo para o emprego de aspas na escrita. Para demonstrar isso, repetimos parte do Fragmento 2, especificamente o trecho em que o pesquisador faz referência ao teórico?

Maingueneau (1997) acrescenta que, diferentemente de uma expressão aspeada de um discurso direto - que remete à alteridade - a palavra entre aspas é utilizada para marcar uma menção e um uso dessa palavra, bem como já foi visto em Authier-Revuz. Nesse caso, a palavra coisa é ao mesmo tempo mostrada, marcada como estranha e integrada à sequência do discurso. [...]

(D2B, p. 90-91)

Recorremos à fonte teórica fornecida pelo pesquisador, a saber: Maingueneau (1997), para contrastar com o texto do pesquisador a partir do modo como mobiliza o discurso do outro ao interpretar a frase: “(6) ‘Que pena que só 
sei escrever quando espontaneamente a 'coisa' vem.'[...]". Representamos, no Quadro 4, a seguir, de um lado, o trecho retirado da fonte teórica e, de outro, o trecho representativo do texto do pesquisador.

Quadro 4 - Comparação entre o texto fonte e o texto do pesquisador

\begin{tabular}{|c|c|}
\hline $\begin{array}{l}\text { Segmentos do texto fonte: } \\
\text { Maingueneau (1997) }\end{array}$ & $\begin{array}{l}\text { Segmentos do texto do pesquisador: } \\
\text { Análise dos dados }\end{array}$ \\
\hline $\begin{array}{l}\text { Os enunciados relatados em discurso direto são postos entre aspas } \\
\text { para marcar sua alteridade, esta última, além disso, é claramente } \\
\text { manifestada pela ruptura sintática entre o discurso que cita e o } \\
\text { discurso citado. Na palavra entre aspas em compensação, esta } \\
\text { ruptura não existe: a expressão aspeada é, ao mesmo tempo usada } \\
\text { e mencionada, dependendo, consequentemente da "conotação } \\
\text { autonímica"... A palavra entre aspas (e/ou em itálico) apresenta a } \\
\text { particularidade de acumular menção e uso. No enunciado "Sinal } \\
\text { dos tempos: a imprensa "feminina" cede no momento em que a } \\
\text { mulher se afirma", a palavra feminina é, ao mesmo tempo, mostra- } \\
\text { da, marcada como estranha e integrada à sequência do enunciado. } \\
\text { (MAINGUENEAU, 1997, p. 89) }\end{array}$ & $\begin{array}{l}\text { Maingueneau (1997) acrescenta que, } \\
\text { diferentemente de uma expressão } \\
\text { aspeada de um discurso direto - que } \\
\text { remete à alteridade - a palavra entre } \\
\text { aspas é utilizada para marcar uma } \\
\text { menção e um uso dessa palavra, bem } \\
\text { como já foi visto em Authier-Revuz. } \\
\text { Nesse caso, a palavra coisa é ao mes- } \\
\text { mo tempo mostrada, marcada como } \\
\text { estranha e integrada à sequência do } \\
\text { discurso. [...] } \\
\text { (D2B, p. 90-91) }\end{array}$ \\
\hline
\end{tabular}

Percebemos que, excetuando-se aspectos como a atribuição da fonte do texto "Maingueneau (1997)", a supressão de informações, como "[...] é, ao mesmo tempo usada e mencionada, dependendo, consequentemente da 'conotação autonímica'... A palavra entre aspas (e/ou em itálico) apresenta a particularidade de acumular menção e uso", o pesquisador sintetiza as informações do conteúdo do conceito de aspas, no trecho "[...] a palavra entre aspas é utilizada para marcar uma menção e um uso dessa palavra, bem como já foi visto em Authier-Revuz". Ademais, cita outro autor, Authier-Re$v u z$, para sustentação do dizer, bem como faz a inversão de palavras (feminina por coisa; enunciado por discurso). Observamos, assim, que não ocorre a paráfrase linguística, que requer do pesquisador interpretar ou reformular com suas próprias palavras o conteúdo que foi dito no texto fonte por Maingueneau (1997, p. 89), que apresenta a frase "a palavra feminina é, ao mesmo tempo, mostrada, marcada como estranha e integrada à sequência do enunciado", vê-se que destaca em itálico a palavra feminina com o intuito de exemplificar que, no contexto em uso, essa palavra representa a particularidade de acumular menção e uso, dependendo, consequentemente, da "conotação autonímica".

Por sua vez, o pesquisador não deu conta desse conteúdo, de parafraseá-lo. Com isso, segue a mesma estrutura sintática da frase citada, como observamos em seu texto produzido, a seguinte frase: "a palavra coisa é ao mesmo tempo mostrada, marcada como estranha e 
integrada à sequência do discurso". Comparando as duas frases, percebemos que o pesquisador constrói seu próprio discurso com trechos do discurso do outro. É o que podemos ver nos trechos:

Segmentos do texto fonte: Maingueneau (1997) - [...] a palavra feminina é, ao mesmo tempo, mostrada, marcada como estranha e integrada à sequência do enunciado (MAINGUENEAU, 1997, p. 89).

Segmentos do texto do pesquisador: Análise dos dados [...] a palavra coisa é ao mesmo tempo mostrada, marcada como estranha e integrada à sequência do discurso (D2B, p. 90-91).

Ao comparar os trechos, é visível que o pesquisador elabora o enunciado repetindo as palavras de Maingueneau (destaque em negrito), que são traduzidas literalmente e reescritas em sua pesquisa. Além disso, o pesquisador substitui palavras (feminina por coisa; enunciado por discurso), mas mantém, no enunciado, a mesma sequência sintática. Assim, o trecho fonte foi encaixado na análise do pesquisador para confirmação do dado analisado e, apesar da evidente alteração de palavras, a dimensão sintática do enunciado é praticamente a mesma. Dito de outro modo, o discurso do outro, nesse caso, de Maingueneau (1997), aparece transcrito e repetido pelo pesquisador na análise da frase, sem se considerar a diferença dos contextos em que foram empregados.

Desse modo, o pesquisador não negocia sentido, transpõe para sua pesquisa a análise de uma frase de Maingueneau (texto fonte), faz a substituição do dado (ex. feminina por coisa; enunciado por discurso), o que consiste em transportar uma frase de sua pesquisa para o discurso de Maingueneau. A frase deixa de ser analisada pelo pesquisador em uma interpretação pessoal.

\section{Considerações finais}

Este trabalho pautou-se no objetivo de investigar o uso das formas linguísticas que inscrevem o outro na linearidade do discurso, focalizando as estratégias mobilizadas pelo pesquisador na negociação com o discurso do outro em seu dizer na dissertação de mestrado. Procuramos, mais especificamente, identificar: a) que formas linguísticas são utilizadas para inserir o discurso do outro e b) como se dá a construção de sentidos do texto considerando-se a negociação de dizeres materializados textualmente. Os fragmentos analisados revelam a dimensão de uma dificuldade dos pesquisadores no desenvolvimento da pesquisa, no que se refere à ação mais ampla de instaurar a negociação (diálogo) com o discurso do outro (autor citado) nos textos acadêmico-científicos.

Nesse contexto, no Fragmento 1, deparamo-nos com a limitação do pesquisador ao interpretar o texto fonte, uma vez que utiliza a estratégia linguística das formas de modalização em discurso segundo, como "Para Brandão (2007)", e o introdutor de discurso indireto, no caso, "Brandão salienta que", que configura, na verdade, reprodução literal das pa- 
lavras do autor citado, mascaradas pela explicitação do nome desse autor citado e pela ausência de aspas. A indicação da fonte e a ausência de aspas seria uma evidência de que o pesquisador, na escrita de seu texto, teria se dado ao trabalho de interpretar e construir sentidos para o texto fonte (lido), mas, ao contrário, ele demonstra a dificuldade de interpretar o texto fonte devido à ausência de apropriação do dizer do outro na produção do texto acadêmico-científico. Como resultado, o discurso do pesquisador fica oculto em seu texto e acaba desempenhado o papel do "outro" na dissertação. Entretanto, o outro deveria ser o autor citado pelo pesquisador, mas, nesse caso, acaba desempenhando o papel de "um" (eu que enuncia) na pesquisa.

No Fragmento 2, percebemos que o pesquisador, ao mobilizar o discurso do outro a partir da tentativa de negociação de sentidos no texto produzido, repete a análise de um dado realizada por Maingueneau (1997), conforme o seguinte excerto: “[...] a palavra feminina é, ao mesmo tempo, mostrada, marcada como estranha e integrada à sequência do enunciado" (MAINGUENEAU, 1997, p. 89). Com base nele, o pesquisador segue a mesma estrutura sintática da frase e, na análise de uma frase em sua pesquisa, escreve: “[...] a palavra coisa é ao mesmo tempo mostrada, marcada como estranha e integrada à sequência do discurso" (p. 90-91). Comparando as duas frases, o pesquisador faz uso da repetição de dado (frase analisada no texto fonte por Maingueneau), em sua pesquisa, o que aponta para a dificuldade em negociar sentidos a partir do conceito lido sobre o emprego das aspas. Como pode ser constatado, o pesquisador não deu conta de parafrasear esse conteúdo. Assim, segue a mesma estrutura sintática e monta seu próprio discurso com trechos do discurso do outro, com substituições de palavras.

Diante do exposto, a análise dos dois fragmentos analisados evidencia que os pesquisadores, nas duas dissertações de mestrado em análise, recorrem às formas linguísticas que sinalizam a introdução do dizer do outro no texto por eles produzido. No entanto, ao comparar o texto fonte com os textos produzidos por eles, compreendemos as dificuldades em relação à inserção do discurso do outro nos trechos produzidos, por não interpretar e nem reformular o conteúdo fonte.

Nesse contexto, parece-nos indispensável propor discussão acerca da abertura para tais questionamentos na universidade sobre a produção escrita hoje, a fim de problematizar as dificuldades dos pesquisadores na prática da escrita na universidade, de modo a construir um lugar na comunidade acadêmica (implicação com o saber) e, consequentemente, a colaborar para a produção do conhecimento científico. 


\section{Research negotiation strategies with speech of others into his/ her own discuss}

\begin{abstract}
This study analyzes 2 dissertations, from the Programa de Pós-graduação em Letras, collected in the Periodical's Portal from CAPES, written between 2007 and 2013 in Brazilian Federal Universities. The main aim is to analyze the use of linguistic forms that insert the other's speech in the linearity of the author discuss, focusing on strategies used by the researcher (author of dissertation) in the negotiation with the other's speech in his/her own text. To the basement of reflections, this study takes, mainly, the linguistic-enunciative studies developed by Authier-Revuz (1990, 1998, 2004, 2011) related to the enunciative heterogeneity of the text and as well as the linguistic paraphrase concept by Fuchs (1985). The data analyzed shows difficult in the writing process in the university related to the use of linguistic forms of introduction of the other speech in the produced text and in the problematization in the production of this process.
\end{abstract}

Keywords: Dissertation. Linguistic forms. Negotiation of discuss.

\section{Notas}

1 Tese em andamento, intitulada Negociação de vozes em dissertação de mestrado e implicações para o ensino da escrita na universidade, desenvolvida no Programa de Pós-Graduação em Estudos da Linguagem da Universidade Federal do Rio Grande do Norte. Eixo temático: Estudos Linguísticos do Texto.
2 Grupo de pesquisa fundado em 2010, no Departamento de Letras na Universidade Federal do Rio Grande do Norte, visando estudos e pesquisas que permeiam o ensino e a aprendizagem da escrita em ambiente escolar/acadêmico.

3 Disponível em: <www.capes.gov.br/servicos/ banco-de-teses $>$. Acesso em: 12 jan. 2016.

4 Marcamos em negrito (repetição do discurso do outro); bordas externas (substituições de palavras); sublinhado duplo (as formas linguísticas de heterogeneidade mostrada), sublinhado simples (sinalizam aspectos de análise). Esses recursos foram destacados para identificar, a partir do texto fonte (lido), os vários modos de movimento realizado pelo pesquisador na negociação com 0 discurso do outro no texto produzido.

\section{Referências}

AUTHIER-REVUZ, J. A. Dizer ao outro no já dito: interferências de alteridades - interlocutiva e interdiscursiva - no coração do dizer. Tradução de Lecci Borges Barbisan. Letras de Hoje, Porto Alegre, v. 46, n. 1, p. 6-20, jan./mar. 2011.

Entre a transparência e a opacidade: um estudo enunciativo do sentido. Tradução de Leci Borges Barbisan e Valdir do Nascimento Flores. Porto Alegre: EDIPUCRS, 2004.

Heterogeneidade(s) enunciativa(s). Cadernos de Estudos Linguísticos, Campinas, n. 19, p. 25-42, jul./dez.1990.

. Palavras incertas: as não coincidências do dizer. Campinas: Unicamp, 1998.

BRANDÃO, H. H. N. Introdução a Análise do Discurso. 2. ed. rev. Campinas: Unicamp, 2007.

CHARAUDEAU, P. "Dize-me qual é teu corpus, eu te direi qual é a tua problemática”. Revista Diadorim - Revista de Estudos Linguísticos e Literários do Programa de Pós-Graduação em Letras Vernáculas da Universidade Federal do Rio de Janeiro, Rio de Janeiro, v. 10, dez. 2011. Disponível em: <http://www.revistadiadorim.letras.ufrj.br>. Acesso em: 12 jun. 2016. 
FUCHS, C. A paráfrase linguística: equivalência, sinonímia ou reformulação? Tradução de João Wanderlei Geraldi. Caderno de Estudos Linguísticos, Campinas, n. 8, p. 129-134, 1985.

MAINGUENEAU, D. Novas tendências em Análises do Discurso. Tradução de Freda Indursky. 3. ed. Campinas: Pontes, 1997.

PÊCHEUX, M. O discurso: estrutura ou acontecimento. Tradução de Eni Pulcinelli Orlandi. Campinas, SP: Pontes, 1990.

PÊCHEUX, M. Semântica e discurso: uma crítica à afírmação do óbvio. Tradução de Eni Orlandi et al. Campinas: Unicamp, 1997. 